\title{
Paraoxonase 1 -L55M polymorphism and coronary heart disease risk in the Chinese population: evidence from a meta-analysis
}

\author{
Kelian ZHANG ${ }^{1}$, Huilin $\mathrm{ZHUO}^{1}$, Jingyi GUO ${ }^{2}$, Delong $\mathrm{LI}^{1}$, Ruozhu DAI ${ }^{1 *}$
}

\begin{abstract}
Many studies have examined the association between paraoxonase 1 (PON1) -L55M polymorphisms and risk of coronary heart disease (CHD), but the results remained inconsistent. We therefore aimed to address this association by performing an updated meta-analysis in the Chinese population. The PubMed, EMBASE, Web of Science, and Chinese National Knowledge Infrastructure were searched up to May 2020. The strength of statistical association was assessed with odds ratio (OR) and 95\% confidence interval (CI). A total of eight studies with $1826 \mathrm{CHD}$ cases and 1817 controls were finally included in the analysis. In the overall and subgroup analyses by control sources and geographic areas, the results showed no significant associations with CHD among all analysis models. Furthermore, we performed the analysis by including or excluding the HWE-violating studies. The results suggested that the MM genetype were significantly associated with CHD in studies not consistent with HWE under recessive and dominant models. This meta-analysis demonstrates that the PON1 -L55M polymorphism may not be associated with CHD risk in the Chinese population. Further studies with strict selection of patients and controls in different ethnic populations will be required to clarify this finding.
\end{abstract}

Keywords: paraoxonase 1; polymorphism; coronary heart disease; genetics; meta-analysis.

Practical Application: This study includes more studies on the Chinese population. In addition, we not only evaluated the impact of risk alleles and coronary heart disease, but also the impact of heterozygotes, homozygotes, and coronary heart disease. Through subgroup analysis, the influence of gene-environment interaction on the risk of coronary heart disease was also studied. In addition, we explored potential sources of heterogeneity across studies and the possibility of publication bias. The sensitivity analysis confirmed the reliability and stability of the meta-analysis.

\section{Introduction}

Coronary heart disease (CHD), one of the major causes of morbidity and mortality worldwide, had become a growing public health problem in developing or lower-income countries (Teo \& Dokainish, 2017). Despite advances in our understanding of cardiovascular disease, detailed pathogenetic mechanisms of $\mathrm{CHD}$ are not fully understood. However, it has been hypothesized that the greatest impact of increased prevalence of CHD may be associated with genetic and environmental predisposing factors (Dalen et al., 2014; Sayols-Baixeras et al., 2014). Paraoxonase 1 (PON1) -L55M (rs854560) has been identified as one of single nucleotide polymorphisms contributing to the CHD susceptibility. The results, however, are not frequently reproducible. In retrospect, individual studies with small sample sizes that are known to have low statistical power and yielded poor replication record. Moreover, this lack of reproducibility might also stem from racial or regional differences and discrepant lifestyle backgrounds. In order to reduce the influence of the diverse backgrounds, we performed a meta-analysis to assess the relationship between PON1 -L55M polymorphism and CHD risk in the Chinese population.

\section{Materials and methods}

\subsection{Identification of eligible studies and data extraction}

We performed the meta-analysis according to the guidelines of the PRISMA group. Genetic association studies published before the end of May 2020 on CHD and PON1 -L55M polymorphism were identified through a search of PubMed, EMBASE, Web of Science, and Chinese National Knowledge Infrastructure without language restrictions. The search keywords were (paraoxonase-1 or PON1) and (CHD or coronary artery disease or coronary heart disease) and (Chinese or China). Additional eligible studies were manually searched from the reference lists. Studies were selected according to the following criteria: (1) studies on the association between PON1 -L55M polymorphism and CHD; (2) independent case-control or cohort studies in humans; (3) providing sufficient genetypes data to calculate the odds ratio (OR) and $95 \%$ confidence interval ( $95 \% \mathrm{CI}$ ); (4) Chinese participants; (5) in the case of duplication with multiple articles publishing data on the same population, the most complete data set was included. Review papers, letters, case reports, meeting abstract or editorial articles were excluded. The following information was abstracted from each study: first author's name, publication year, control sources, geographic areas, sample size, frequency of 
genotypes and consistency of genotype frequencies with HardyWeinberg equilibrium (HWE) in controls. Control sources were divided into population-based control (PB) and hospital-based control (HB). The quality assessment of individual study was conducted according to the nine-star Newcastle-Ottawa Scale (Wells et al., 2000).

\subsection{Statistical analysis}

The strength of association between PON1 -L55M polymorphism and CHD susceptibility was assessed with ORs and 95\% CIs. Deviation from HWE was examined by Chisquare test. The meta-analysis examined the overall association of $\mathrm{M}$ allele with the risk of CHD relative to the L allele; and the contrast of homozygotes MM versus LL, the contrast MM versus $(\mathrm{LL}+\mathrm{LM})$, and the contrast $(\mathrm{MM}+\mathrm{LM})$ versus LL. Heterogeneity of pooled results as well as Hardy-Weinberg equilibrium (HWE) in controls was assessed by I-squared statistic based on Q-test . The random-effects model was applied to estimate the pooled ORs when Pheterogeneity $<0.1$ or I $>50 \%$; otherwise, the fixedeffects model was adopted. The significance of the pooled ORs were evaluated by a Z-test. Sensitivity analysis was performed by removing each individual study in turn from the total and re-analyzing the remainder. Publication bias was assessed with Begg's funnel plot and Egger's linear regression test. All statistical analyses were conducted using the Stata, version 12 (StataCorp LP, College Station, TX). A P value less than 0.05 was considered to be statistically significant.

\section{Results}

\subsection{Description of included studies}

Figure 1 illustrates the literature search process with a flow chart. Seventy-nine articles which examined the association between PON1 -L55M polymorphisms and CHD were identified. According to the inclusion and exclusion criteria, eight studies (Sanghera et al., 1998; Wang et al., 2003; Chi et al., 2006;

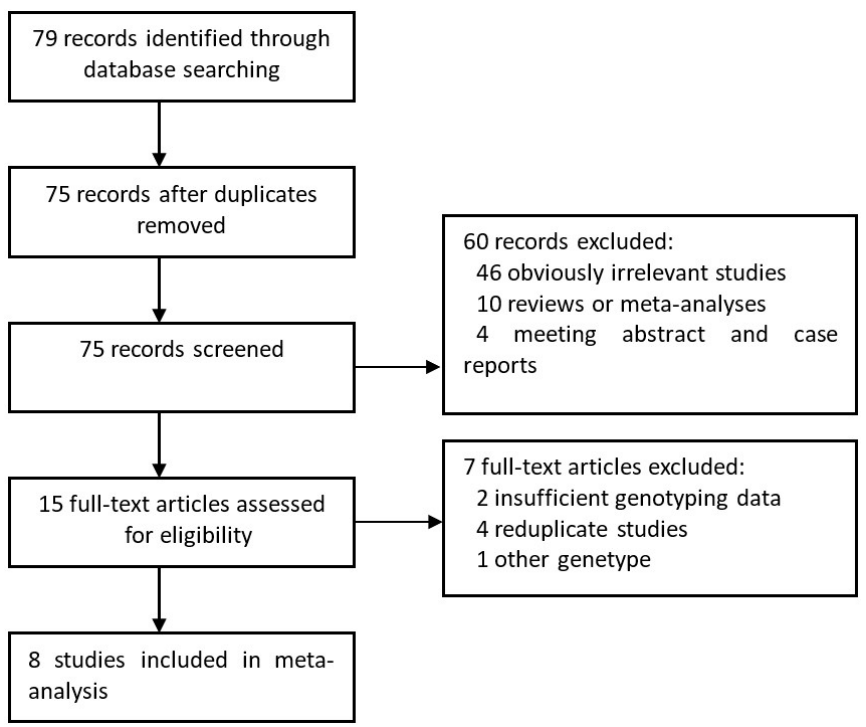

Figure 1. Flow diagram of the literature search.
Yang et al., 2007; Zhou et al., 2009; Wang, 2011; Kang et al., 2013; Mo et al., 2016) were finally included in the analysis. The publication year of involved studies ranged from 1998 to 2016. In total, 1826 CHD cases and 1817 controls were included in this meta-analysis. The source of controls in two included studies was population-based, others were hospital-based studies. PON1 -L55M polymorphisms in controls were found to occur in frequencies consistent with HWE in four studies. The main study characteristic were provided in Table 1.

\subsection{Meta-analysis results}

Overall, the per-allele OR of the 55M variant for $\mathrm{CHD}$ was 1.10 (95\% CI = 0.76-1.59), with corresponding results for homozygotes, recessive and dominant models of 0.76 (95\% CI $=0.46-1.27)$, 0.76 (95\% CI $=0.46-1.26)$ and 1.18 (95\% CI $=0.78-1.76$, respectively (Table 2 ). In the stratified analysis by control sources and geographic areas, no significant associations between the L55M polymorphism and CHD risk were detected in all genetic models (Table 2). Furthermore, we performed the analysis by including or excluding the HWE-violating studies. The results suggested that the MM genetype were significantly associated with $\mathrm{CHD}$ in HWE-violating studies under all recessive and dominant models (MM vs. LL: OR = 0.40, 95\%CI = 0.16-0.98; MM vs. $\mathrm{LL}+\mathrm{LM}: \mathrm{OR}=0.38,95 \% \mathrm{CI}=0.16-0.95$, Table 2, Figure 2).

\subsection{Sensitivity analysis and publication bias diagnosis}

Sensitivity analysis indicated that no single study influenced the pooled OR qualitatively, suggesting that the results of this meta-analysis are stable (Figure 3 ). The shape of the funnel plot was symmetrical (Figure 4A). The Egger's linear regression statistical results still did not show publication bias in these studies for L55M ( $t=-0.30, p=0.779$, Figure $4 \mathrm{~B})$.

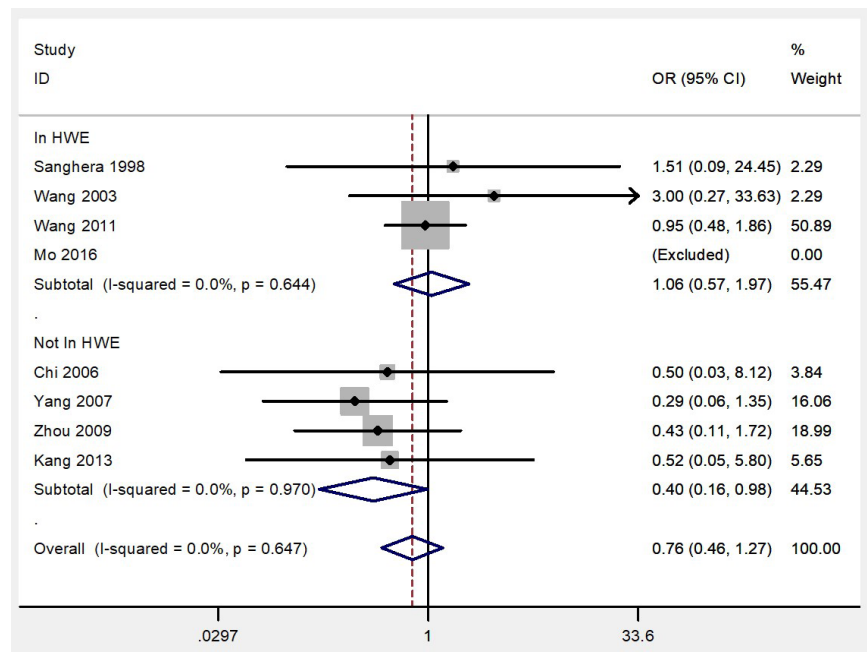

Figure 2. The forest plot on the association between PON1 -L55M polymorphism and CHD susceptibility under homozygotes model. 
Table 1. Characteristics of studies included in the meta-analysis.

\begin{tabular}{|c|c|c|c|c|c|c|c|c|c|c|c|c|c|}
\hline \multirow{2}{*}{ References } & \multirow{2}{*}{$\begin{array}{l}\text { Control } \\
\text { sources }\end{array}$} & \multirow{2}{*}{$\begin{array}{c}\text { Geographic } \\
\text { area }\end{array}$} & \multirow{2}{*}{$\begin{array}{c}\text { Case } \\
\text { number }\end{array}$} & \multirow{2}{*}{$\begin{array}{l}\text { Control } \\
\text { number }\end{array}$} & \multicolumn{3}{|c|}{ Cases } & \multicolumn{3}{|c|}{ Controls } & \multicolumn{2}{|c|}{ HWE } & \multirow{2}{*}{$\begin{array}{c}\text { Quality } \\
\text { score }\end{array}$} \\
\hline & & & & & $\mathrm{LL}$ & $\mathrm{LM}$ & MM & LL & $\mathrm{LM}$ & $\mathrm{MM}$ & $x^{2}$ & $\mathrm{P}$ & \\
\hline Sanghera et al. (1998) & PB & Beijing & 120 & 182 & 111 & 8 & 1 & 168 & 13 & 1 & 1.68 & 0.195 & 8 \\
\hline Wang et al. (2003) & $\mathrm{HB}$ & Beijing & 93 & 138 & 82 & 9 & 2 & 123 & 14 & 1 & 0.7 & 0.403 & 7 \\
\hline Chi et al. (2006) & $\mathrm{PB}$ & Guangdong & 263 & 103 & 197 & 65 & 1 & 99 & 3 & 1 & 15.27 & 0 & 7 \\
\hline Yang et al. (2007) & $\mathrm{HB}$ & Hebei & 151 & 61 & 126 & 22 & 3 & 49 & 8 & 4 & 10.99 & 0.001 & 8 \\
\hline Zhou et al. (2009) & $\mathrm{HB}$ & Sichuan & 86 & 89 & 72 & 11 & 3 & 72 & 10 & 7 & 23.92 & 0 & 8 \\
\hline Wang (2011) & $\mathrm{HB}$ & Shanghai & 437 & 616 & 317 & 105 & 15 & 441 & 153 & 22 & 3.51 & 0.061 & 8 \\
\hline Kang et al. (2013) & $\mathrm{HB}$ & Guangdong & 516 & 536 & 491 & 24 & 1 & 515 & 19 & 2 & 13.01 & 0 & 7 \\
\hline Mo et al. (2016) & $\mathrm{HB}$ & Guangdong & 160 & 92 & 156 & 4 & 0 & 89 & 3 & 0 & 0.03 & 0.874 & 8 \\
\hline
\end{tabular}

Table 2. Association of the PON1 -L55M polymorphism and CHD susceptibility.

\begin{tabular}{|c|c|c|c|c|c|}
\hline \multicolumn{2}{|c|}{ Analysis model } & \multirow{2}{*}{$\frac{n}{8}$} & \multirow{2}{*}{$\frac{\mathrm{OR}_{\mathrm{r}}(95 \% \mathrm{CI})}{1.10(0.76-1.59)}$} & \multirow{2}{*}{$\begin{array}{c}\mathrm{OR}_{\mathrm{f}}(95 \% \mathrm{CI}) \\
1.08(0.90-1.28)\end{array}$} & \multirow{2}{*}{\begin{tabular}{|c|}
$P_{h}$ \\
0.013
\end{tabular}} \\
\hline M vs. L & Total analysis & & & & \\
\hline & Population-based & 2 & $2.41(0.41-14.23)$ & $2.73(1.57-4.75)$ & 0.004 \\
\hline & Hospital-based & 6 & $0.94(0.78-1.14)$ & $0.94(0.78-1.14)$ & 0.719 \\
\hline & North China & 3 & $0.91(0.59-1.38)$ & $0.91(0.59-1.40)$ & 0.489 \\
\hline & South China & 5 & $1.25(0.71-2.20)$ & $1.11(0.92-1.35)$ & 0.003 \\
\hline & In HWE & 4 & $0.98(0.79-1.21)$ & $0.98(0.79-1.21)$ & 0.927 \\
\hline & Not in HWE & 4 & $1.28(0.56-2.93)$ & $1.31(0.95-1.79)$ & 0.001 \\
\hline \multirow[t]{7}{*}{ MM vs. LL } & Total analysis & 7 & $0.76(0.45-1.27)$ & $0.76(0.46-1.27)$ & 0.647 \\
\hline & Population-based & 2 & $0.87(0.12-6.24)$ & $0.88(0.12-6.30)$ & 0.583 \\
\hline & Hospital-based & 5 & $0.75(0.44-1.28)$ & $0.76(0.45-1.28)$ & 0.420 \\
\hline & North China & 3 & $0.82(0.18-3.71)$ & $0.73(0.24-2.23)$ & 0.229 \\
\hline & South China & 4 & $0.78(0.44-1.38)$ & $0.77(0.44-1.37)$ & 0.744 \\
\hline & In HWE & 3 & $1.05(0.56-1.97)$ & $1.06(0.57-1.97)$ & 0.644 \\
\hline & Not in HWE & 4 & $0.39(0.16-0.96)$ & $0.40(0.16-0.98)$ & 0.970 \\
\hline \multirow[t]{7}{*}{ MM vs. LL+LM } & Total analysis & 7 & $0.76(0.45-1.26)$ & $0.76(0.46-1.26)$ & 0.609 \\
\hline & Population-based & 2 & $0.77(0.11-5.50)$ & $0.79(0.11-5.66)$ & 0.497 \\
\hline & Hospital-based & 5 & $0.75(0.44-1.29)$ & $0.76(0.45-1.28)$ & 0.401 \\
\hline & North China & 3 & $0.82(0.18-3.76)$ & $0.72(0.24-2.21)$ & 0.223 \\
\hline & South China & 4 & $0.78(0.44-1.37)$ & $0.77(0.44-1.36)$ & 0.690 \\
\hline & In HWE & 3 & $1.06(0.57-1.99)$ & $1.07(0.57-1.98)$ & 0.648 \\
\hline & Not in HWE & 4 & $0.38(0.15-0.93)$ & $0.38(0.16-0.95)$ & 0.976 \\
\hline \multirow[t]{7}{*}{ MM+LM vs. LL } & Total analysis & 8 & $1.18(0.78-1.76)$ & $1.14(0.94-1.39)$ & 0.014 \\
\hline & Population-based & 2 & $2.79(0.32-24.53)$ & $3.13(1.74-5.62)$ & 0.001 \\
\hline & Hospital-based & 6 & $0.97(0.78-1.20)$ & $0.97(0.78-1.20)$ & 0.937 \\
\hline & North China & 3 & $0.94(0.59-1.51)$ & $0.95(0.59-1.52)$ & 0.865 \\
\hline & South China & 5 & $1.38(0.72-2.63)$ & $1.19(0.96-1.48)$ & 0.002 \\
\hline & In HWE & 4 & $0.96(0.75-1.23)$ & $0.96(0.75-1.23)$ & 0.978 \\
\hline & Not in HWE & 4 & $1.53(0.62-3.74)$ & $1.60(1.13-2.26)$ & 0.001 \\
\hline
\end{tabular}

OR, odds ratio; $95 \% \mathrm{CI}$, $95 \%$ confidence interval; $\mathrm{P}$, statistical difference.

\section{Discussion}

Although the multifactorial nature of CHD is well known, genetic factors are considered to be strong determinants of these diseases (Jouki et al., 2020; Lorenzo et al., 2021; Wang \& Jin, 2021). Thus encouraging researchers to search for the responsible genes. PON1 gene are known to determine strongly the activity of serum paraoxonase against exogenous substances (such as organophosphates) (Adkins et al., 1993; SapianRaczkowska et al., 2010; Goswami et al., 2009; Yilmaz et al., 2010). Thus, many association studies have reported on
PON1 -L55M polymorphism and CHD (Cascorbi et al., 1999; Mackness et al., 2001; Watzinger et al., 2002; Likidlilid et al., 2010; Ahmad et al., 2012). These studies have yielded apparently conflicting results, perhaps partly because of small sample sizes, racial or regional differences. Till now, there are two published meta-analyses regarding PON1 -L55M polymorphisms and CHD risk (Wheeler et al., 2004; Wang, 2011). Both of the two metaanalyses reported that there is no significant association between PON1 -L55M polymorphism and CHD risk. No meta-analysis has been conducted in a separate ethnic group. Therefore, we performed this meta-analysis to assess the relationship between 


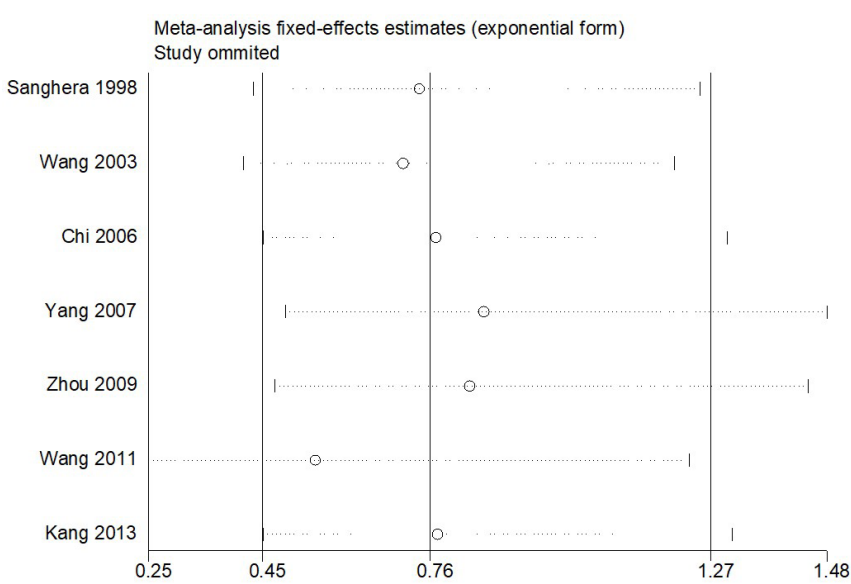

Figure 3. Sensitivity analysis to evaluate the stability of the meta-analysis.

PON1 -L55M polymorphism and CHD risk in the Chinese population.

Our meta-analysis involved eight studies with $1826 \mathrm{CHD}$ cases and 1817 controls. In the overall and subgroup analyses by control sources and geographic areas, the results showed no significant associations with $\mathrm{CHD}$ among all analysis models. The findings were consistent with the previous meta-analyses (Wheeler et al., 2004; Wang, 2011). The controls in four cohorts (Chi et al., 2006; Yang et al., 2007; Zhou et al., 2009; Kang et al., 2013) were not consistency with HWE $(\mathrm{P}<0.05)$, which contributes more than $40 \%$ of the controls included in the study. Therefore, we further performed the analysis by including or excluding HWE-violating studies in control groups, the results also showed no significant association between PON1 -L55M polymorphism and CHD risk in the studies consistent with HWE. However, we found a significantly decreased risk association between PON1 -L55M polymorphism and CHD risk in studies not consistent with $\mathrm{HWE}$ ( $\mathrm{MM}$ vs. $\mathrm{LL}: \mathrm{OR}=0.40,95 \% \mathrm{CI}=0.16-0.98 ; \mathrm{MM}$ vs. $\mathrm{LL}+\mathrm{LM}$ : $\mathrm{OR}=0.38,95 \% \mathrm{CI}=0.16-0.95)$.

Compared with the previous meta-analysis (Wheeler et al., 2004; Wang, 2011), the present study included a larger number of studies, which were conducted in Chinese population. In addition, we assessed not only the effect of risk allele and CHD but also the effects between heterozygous, and homozygous and CHD. And the effects of gene-environment interactions with respect to CHD risk were also conducted by the subgroup analyses. Furthermore, we explored potential sources of heterogeneity across studies and the possibility of publication bias. The sensitivity analysis confirmed the reliability and stability of the metaanalysis. Our results suggest an overestimation of the true genetic association between PON1 -L55M polymorphism and CHD risk in the Chinese population. However, this ethnic-specific meta-analysis only included data from Chinese patients, and thus, further studies are needed to assess the association in other population. In addition, the etiology of CHD is complex and is mediated by the activities of multiple genes. The effect of any single gene might have a limited impact on CHD risk so far. Finally, due to half of the included studies with HWE-violating controls, it may affect the authenticity of the results.

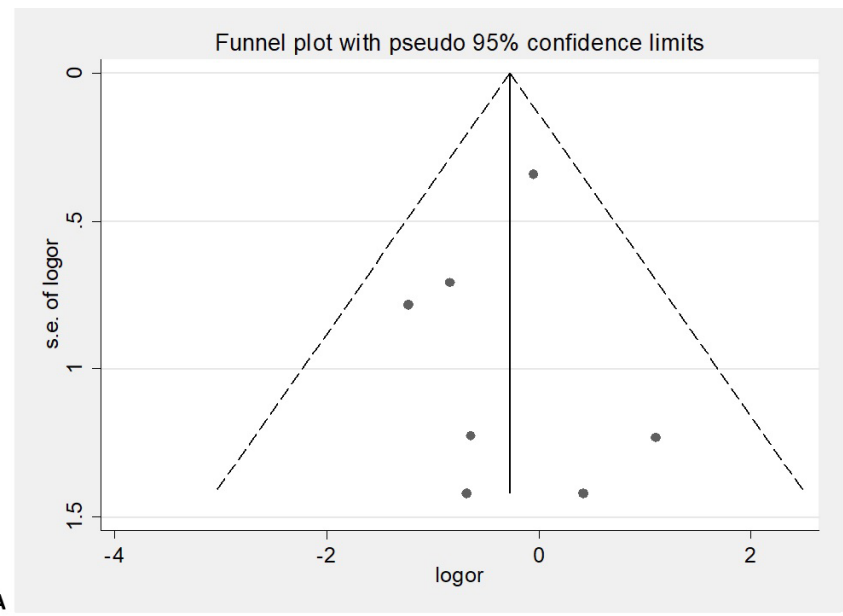

A

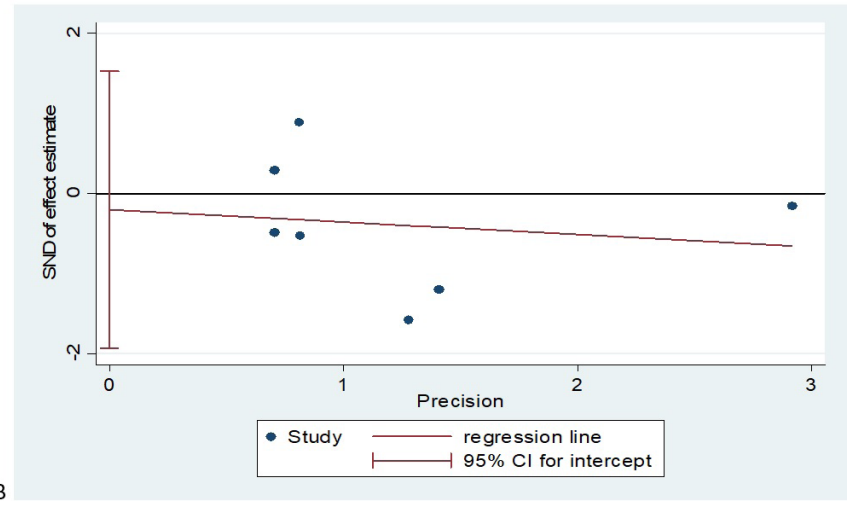

Figure 4. Publication bias assessment with (A) Begg's funnel plot and (B) Egger test.

In conclusion, this meta-analysis demonstrated that the PON1 -L55M polymorphism may not be associated with the CHD risk in the Chinese population. For future association studies, strict selection of patients and controls, larger studies of different ethnic populations will be required to clarify the findings.

\section{References}

Adkins, S., Gan, K. N., Mody, M., \& La Du, B. N. (1993). Molecular basis for the polymorphic forms of human serum paraoxonase/ arylesterase: glutamine or arginine at position 191, for the respective A or B allozymes. American Journal of Human Genetics, 52(3), 598608. PMid:7916578.

Ahmad, I., Narang, R., Venkatraman, A., \& Das, N. (2012). Two-and three-locus haplotypes of the paraoxonase (PON1) gene are associated with coronary artery disease in Asian Indians. Gene, 506(1), 242247. http://dx.doi.org/10.1016/j.gene.2012.06.031. PMid:22750797.

Cascorbi, I., Laule, M., Mrozikiewicz, P. M., Mrozikiewicz, A., Andel, C., Baumann, G., Roots, I., \& Stangl, K. (1999). Mutations in the human paraoxonase 1 gene: frequencies, allelic linkages, and association with coronary artery disease. Pharmacogenetics, 9(6), 755-761. http:// dx.doi.org/10.1097/00008571-199912000-00010. PMid:10634138.

Chi, D. S., Ling, W. H., Ma, J., Xia, M., Hou, M. J., Wang, Q., Zhu, H. L., Tang, Z. H., \& Yu, X. P. (2006). Study of the association between paraoxonase1 $55 \mathrm{Met} / \mathrm{Leu}$, paraoxonase $148 \mathrm{Ala} / \mathrm{Gly}$ and manganese 
superoxide dismutase (MnSOD) 9 Ala/Val genetic polymorphisms and coronary heart disease. Zhonghua Liu Xing Bing Xue Za Zhi, 27(9), 808-813. PMid:17299970.

Dalen, J. E., Alpert, J. S., Goldberg, R. J., \& Weinstein, R. S. (2014). The epidemic of the 20(th) century: coronary heart disease. The American Journal of Medicine, 127(9), 807-812. http://dx.doi.org/10.1016/j. amjmed.2014.04.015. PMid:24811552.

Goswami, B., Tayal, D., Gupta, N., \& Mallika, V. (2009). Paraoxonase: a multifaceted biomolecule. Clinica Chimica Acta, 410(1-2), 1-12. http://dx.doi.org/10.1016/j.cca.2009.09.025. PMid:19799889.

Jouki, M., Rabbani, M., \& Shakouri, M. J. (2020). Effects of pectin and tomato paste as a natural antioxidant on inhibition of lipid oxidation and production of functional chicken breast sausage. Food Science and Technology, 40(Suppl. 2), 521-527. http://dx.doi. org/10.1590/fst.26419.

Kang, Y. H., Lao, H. Y., Wu, H., Lai, W. H., Li, X. X., Yu, X. Y., Chen, J. Y., \& Zhong, S. L. (2013). Association of PON1 genotype and haplotype with susceptibility to coronary artery disease and clinical outcomes in dual antiplatelet-treated Han Chinese patients. European Journal of Clinical Pharmacology, 69(8), 1511-1519. http://dx.doi. org/10.1007/s00228-013-1516-6. PMid:23608957.

Likidlilid, A., Akrawinthawong, K., Poldee, S., \& Sriratanasathavorn, C. (2010). Paraoxonase 1 polymorphisms as the risk factor of coronary heart disease in a Thai population. Acta Cardiologica, 65(6), 681691. http://dx.doi.org/10.1080/AC.65.6.2059866. PMid:21302675.

Lorenzo, N. D., Santos, O., \& Lannes, S. (2021). Fatty acid composition, cardiovascular functionality, thermogravimetric-differential, calorimetric and spectroscopic behavior of pequi oil (Caryocar villosum (Alb.) Pers.). Food Science and Technology, 41(2), 524-529. http://dx.doi.org/10.1590/fst.16420.

Mackness, B., Davies, G., Turkie, W., Lee, E., Roberts, D. H., Hill, E., Roberts, C., Durrington, P. N., \& Mackness, M. I. (2001). Paraoxonase status in coronary heart disease: are activity and concentration more important than genotype? Arteriosclerosis, Thrombosis, and Vascular Biology, 21(9), 1451-1457. http://dx.doi.org/10.1161/hq0901.094247. PMid:11557671.

Mo, Y. H., Hu, X. S., Zhang, X. X., Chen, X. Y., Zhang, W. B., Wu, J. S., \& Wu, G. F. (2016). Relationship between Serum Paraoxonase-1 level and gene L55M locus polymorphism and coronary disease. Practical Journal of Cardiac Cerebral Pneumal and Vascular Disease, 24, 133-134.

Sanghera, D. K., Saha, N., \& Kamboh, M. I. (1998). The codon 55 polymorphism in the paraoxonase 1 gene is not associated with the risk of coronary heart disease in Asian Indians and Chinese. Atherosclerosis, 136(2), 217-223. http://dx.doi.org/10.1016/S00219150(97)00206-2. PMid:9543091.

Sapian-Raczkowska, B., Rabczyński, M., \& Adamiec, R. (2010). Paraoxonase: important enzyme of the lipid metabolism and potential ally in the antiatherosclerotic treatment. Polski Merkuriusz Lekarski, 29(173), 325-327. PMid:21268919.

Sayols-Baixeras, S., Lluís-Ganella, C., Lucas, G., \& Elosua, R. (2014). Pathogenesis of coronary artery disease: focus on genetic risk factors and identification of genetic variants. The Application of Clinical Genetics, 7, 15-32. http://dx.doi.org/10.2147/TACG.S35301. PMid:24520200.

Teo, K. K., \& Dokainish, H. (2017). The emerging epidemic of cardiovascular risk factors and atherosclerotic disease in developing countries. The Canadian Journal of Cardiology, 33(3), 358-365. http:// dx.doi.org/10.1016/j.cjca.2016.12.014. PMid:28232018.

Wang, J., \& Jin, D. (2021). Study on the mechanism and therapeutic effect of Antelope horn treatment on cerebral ischemia reperfusion injury of mouse. Food Science and Technology, 41(Suppl. 1), 142-149. http://dx.doi.org/10.1590/fst.35119.

Wang, M. S. (2011). Studies on association and meta-analysis of genetic variations of paraoxonase gene in coronary heart disease (Ph.D. thesis). Second Military Medical University, China.

Wang, X. D., Fu, Y., \& Jiang, H. J. (2003). Study of paraoxonase 1 gene polymorphisms in coronary heart disease. Journal of Clinical Cardiology, 19, 724-726.

Watzinger, N., Schmidt, H., Schumacher, M., Schmidt, R., Eber, B., Fruhwald, F. M., Zweiker, R., Kostner, G. M., \& Klein, W. (2002). Human paraoxonase 1 gene polymorphisms and the risk of coronary heart disease:a community-based study. Cardiology, 98(3), 116-122. http://dx.doi.org/10.1159/000066321. PMid:12417809.

Wells, G. A., Shea, B., O'Connell, D., Peterson, J., Welch, V., Losos, M., \& Tugwell, P. (2000). The Newcastle-Ottawa Scale (NOS) for assessing the quality if nonrandomized studies in meta-analyses. Retrieved from http://www.ohri.ca/programs/clinical_epidemiology/oxford.asp

Wheeler, J. G., Keavney, B. D., Watkins, H., Collins, R., \& Danesh, J. (2004). Four paraoxonase gene polymorphisms in 11212 cases of coronary heart disease and 12786 controls: meta-analysis of 43 studies. Lancet, 363(9410), 689-695. http://dx.doi.org/10.1016/ S0140-6736(04)15642-0. PMid:15001326.

Yang, Y. H., Xia, Y., Cui, D. S., Yuan, S. H., Geng, Y. L., Qi, G. Q., Liu, G., \& Liu, K. S. (2007). Study on the relationship among the codon 55,192 gene polymorphisms of paraoxonase- 1 and coronary disease as well as its severity of stenosis. Journal of Clinical Cardiology., 23, 566-569.

Yilmaz, H., Sayar, N., Yilmaz, M., Gurkan, U., Sesal, C., Tosu, R., Cakmak, N., Erer, B., Oz, D., Ciloglu, F., \& Bolca, O. (2010). Serum paraoxonase 1 activity in women with metabolic syndrome. Kardiologia Polska, 68(11), 1219-1224. PMid:21108196.

Zhou, H., Lu, Z. C., Gao, Z., Long, Y., \& Tian, H. M. (2009). Relationships between PON1 L55M polymorphism and coronary heart diseases complicated with fasting hyperglycemia in Han Populations in Guangdong. Journal of Sichuan University. Medical Science Edition, 40(1), 68-72. PMid:19292048. 